This document is the Accepted Manuscript version of a Published Work that appeared in final form in Analytical Chemistry, (C) 2016 American Chemical Society after peer review and technical editing by publisher. To access the final edited and published work see Huang, P.-J. J., \& Liu, J. (2016). An Ultrasensitive Light-up Cu2+ Biosensor Using a New DNAzyme Cleaving a Phosphorothioate-Modified Substrate. Analytical Chemistry, 88(6), 3341-3347. https://doi.org/10.1021/acs.analchem.5b04904

\title{
An Ultrasensitive Light-up $\mathrm{Cu}^{2+}$ Biosensor Using a New DNAzyme Cleaving a Phosphorothioate Modified Substrate
}

Po-Jung Jimmy Huang and Juewen Liu*

Department of Chemistry, Waterloo Institute for Nanotechnology, University of Waterloo, Waterloo,

Ontario, Canada, N2L 3G1.

*Email: liujw@uwaterloo.ca 


\begin{abstract}
$\mathrm{Cu}^{2+}$ is a very important metal ion in biology, environmental science, and industry. Developing biosensors for $\mathrm{Cu}^{2+}$ is a key topic in analytical chemistry. DNAzyme-based sensors are highly attractive for their excellent sensitivity, stability, and programmability. In the past decade, a few $\mathrm{Cu}^{2+}$ biosensors were reported using DNAzymes with DNA cleavage or DNA ligation activity. However, they require unstable ascorbate or imidazole activation. So far, no RNA-cleaving DNAzymes specific for $\mathrm{Cu}^{2+}$ are known. In this work, a phosphorothioate (PS) RNA containing library was used for in vitro selection, and a few new $\mathrm{Cu}^{2+}$-specific RNA-cleaving DNAzymes were isolated. Among them, a DNAzyme named PSCu10 was studied further. It has only eight nucleotides in the enzyme loop with a cleavage rate of $0.1 \mathrm{~min}^{-1}$ in the presence of $1 \mu \mathrm{M} \mathrm{Cu}^{2+}$ at pH 6.0 (its optimal pH). Between the two diastereomers of the PS RNA chiral center, the $R_{\mathrm{p}}$ isomer is 37 times more active than the $S_{\mathrm{p}}$ one. Among the other divalent metal ions, only $\mathrm{Hg}^{2+}$ can cleave the substrate due to its extremely high thiophilicity. A catalytic beacon sensor was designed with a detection limit of $1.6 \mathrm{nM} \mathrm{Cu}^{2+}$ and extremely high selectivity. PSCu10 is specific for $\mathrm{Cu}^{2+}$ and it has no cleavage in the presence of ascorbate, which reduces $\mathrm{Cu}^{2+}$ to $\mathrm{Cu}^{+}$.
\end{abstract}




\section{Introduction}

Copper is a very common metal used for numerous applications, which has led to increasing environmental concerns. While copper is an essential element for life (e.g. found in many protein enzymes), exposure to a high concentration of copper causes liver, gastrointestinal, and kidney damage. ${ }^{1}$ To cope with copper contamination, improve industrial waste management, and study the metal intracellularly, effective copper sensors are needed. Many copper sensors were designed based on small molecules, ${ }^{2-4}$ peptides,${ }^{5}$ proteins, ${ }^{6}$ and nanomaterials. ${ }^{7}$ While they are responsive to copper ions, some suffer from strong fluorescence quenching by the paramagnetic $\mathrm{Cu}^{2+}$ (i.e. signal-off sensors), poor selectivity or sensitivity, or probe denaturation.

In the past two decades, DNAzymes have emerged as a very useful platform for metal sensing. ${ }^{8-11}$ DNAzymes are DNA-based catalysts that often require divalent metal ions for activity. ${ }^{12-14}$ In vitro selection has been intentionally carried out in the presence of specific metal ions to isolate sensor DNAzymes. ${ }^{15,16} \mathrm{~A} \mathrm{Cu}^{2+}$ biosensor was reported using a DNAzyme that performs oxidative DNA cleavage. ${ }^{17,18}$ While it reached a detection limit of $35 \mathrm{nMCu}^{2+}$, this assay required ascorbate, which is an unstable chemical. Another $\mathrm{Cu}^{2+}$-dependent DNA ligating DNAzyme was also made into $\mathrm{Cu}^{2+}$ sensors. ${ }^{19,20}$ However, this DNAzyme requires an unstable imidazole activated substrate. $\mathrm{Cu}^{2+}$ was also used as a cofactor to isolate other DNAzymes, ${ }^{21,22}$ but it was not the sole metal in those cases.

To date, the best developed DNAzymes for metal sensing are those cleaving RNA. For example, RNA-cleaving DNAzymes specific for $\mathrm{Na}^{+}, 23,24 \mathrm{~Pb}^{2+}, 25,26 \mathrm{Zn}^{2+},{ }^{27} \mathrm{UO}_{2}{ }^{2+},{ }^{28}$ and lanthanide ions ${ }^{29-31}$ were reported. These DNAzymes are fast, highly selective, and versatile in biosensor design. These metals are either hard or borderline Lewis acids, while it is quite challenging to obtain sensor DNAzymes for soft metals. The natural DNA has only four types of 
nucleobases connected by phosphates with limited chemical functionality. To isolate DNAzymes that work with thiophilic metals, modified nucleotides containing imidazole and amine groups were tested yielding new $\mathrm{Zn}^{2+}$ and $\mathrm{Hg}^{2+}$ specific DNAzymes. ${ }^{32,33}$ However, these modified nucleotides are not commercially available and the selection process is quite technically demanding, limiting their general analytical applications.

We reason that an alternative solution is to introduce a phosphorothioate (PS) modification at the cleavage site. ${ }^{34}$ A PS modification refers to replacing one of the non-bridging oxygen atoms in the phosphate by a sulfur, which is known to recruit thiophilic metals. The PS modification has been used for probing ribozyme mechanisms, designing anti-sense oligonucleotides, and assembling nanomaterials. ${ }^{35-40}$ Since $\mathrm{Cu}^{2+}$ is a thiophilic soft metal, we herein use a PS containing library for selecting new DNAzymes in the presence of $\mathrm{Cu}^{2+}$, and develop a biosensor for $\mathrm{Cu}^{2+}$ detection.

\section{Materials and Methods}

Chemicals. The DNAs used in this work were from Integrated DNA Technologies (Coralville, IA) and Eurofins (Huntsville, AL). Noted that the DNA sequences related to in vitro selection are listed in Table S1 and the other DNAs are shown in Table S2. Tris(hydroxymethyl)aminomethane (Tris), 2-(N-morpholino)ethanesulfonic acid (MES), 2-[4-(2-hydroxyethyl)piperazin-1-yl]ethanesulfonic acid (HEPES), ethylenediaminetetraacetic acid disodium salt (EDTA), sodium chloride, and ammonium acetate were from Mandel Scientific (Guelph, Ontario, Canada). 3-(NMorpholino)propanesulfonic acid (MOPS), agarose M, urea, 40\% acryl/bis solution (29:1), and

10× TBE were from Bio Basic (Markham, Ontario, Canada). SsoFast EvaGreen supermix was from Bio-Rad. T4-DNA ligase, dNTP mix, Taq DNA polymerase, gel loading dye (6×) and DNA 
ladder were from New England Biolabs. Barium (II) chloride dihydrate, cadmium (II) chloride hydrate, calcium chloride, cobalt (II) chloride hexahydrate, copper (II) chloride dihydrate, iron (III) chloride hexahydrate, lead acetate, magnesium chloride, manganese (II) chloride tetrahydrate , mercury (II) perchlorate hydrate, nickel (II) chloride hexahydrate, tetrakis(acetonitrile)copper (I) hexafluorophosphate, and zinc chloride were from Sigma-Aldrich at the highest available purity.

In vitro selection. The selection has largely followed a previously reported method, ${ }^{34}$ except that the metal cofactor was changed to $\mathrm{Cu}^{2+}$. Briefly, the initial library was prepared by ligating LibFAM (0.2 nmol) and Lib-rA* $(0.3 \mathrm{nmol})$ with a splint DNA (0.3 nmol) using T4 ligase following the vendor's protocol. The ligated DNA was purified with $10 \%$ denaturing polyacrylamide gel electrophoresis (dPAGE) and extracted from the gel with buffer A (1 mM EDTA, $10 \mathrm{mM}$ Tris$\mathrm{HCl}, \mathrm{pH}$ 7.0). The full length DNA library was desalted with a Sep-Pak C18 column (Waters) and lyophilized overnight. The library was re-suspended in $60 \mu \mathrm{L}$ buffer B (50 mM MES, pH 6.0, 25 $\mathrm{mM} \mathrm{NaCl}$ ) and $5 \mu \mathrm{L}$ was used for the first round of selection. For each subsequent round, the DNA library was generated from polymerase chain reaction (PCR). The selection condition for each round is listed in Figure 1B.

Biochemical assays. In a typical assay, the DNAzyme complex was formed with carboxyfluorescein (FAM)-labeled PS substrate $(5 \mu \mathrm{M})$ and enzyme $(7.5 \mu \mathrm{M})$ in buffer B. For gelbased assay, each sample contains a final of $5 \mu \mathrm{L}$ of $0.7 \mu \mathrm{M}$ DNAzyme complex. Metal salts were diluted with Milli-Q water and $2 \mu \mathrm{L}$ of metal solution was added to initiate the cleavage reaction. The reaction was quenched by $8 \mu \mathrm{L}$ of $1 \times$ gel loading dye containing $8 \mathrm{M}$ urea at a designated time. The products were then separated on 15\% dPAGE gels and analyzed using a ChemiDoc MP imaging system (Bio-Rad). All assays were run at least in duplicate. The cleavage kinetic were fit using the following equation: $y=y_{0}+a(1-\exp (-k x))$, where $k$ is the cleavage rate. 
Biosensor assays. The sensor complex was formed by annealing the FAM-labeled PS substrate (5 $\mu \mathrm{M}$, after 17E treatment) and the quencher-labeled enzyme $(7.5 \mu \mathrm{M})$ in buffer $\mathrm{B}$. The sensing kinetics were performed in a 96-well plate. For each well, $100 \mu \mathrm{L}$ of the sensor (final $50 \mathrm{nM}$ ) in buffer $\mathrm{C}$ (50 mM MES, pH 6.0, $5 \mathrm{mM} \mathrm{NaCl})$ was used. One microliter metal ion was added to initiate cleavage and the signaling kinetics was monitored $(E x=485 \mathrm{~nm} ; E m=520 \mathrm{~nm})$ using a microplate reader (M3, SpectraMax).

$\mathrm{Cu}^{2+}$ detection in lake water. Water samples from Lake Ontario were passed through a $0.2 \mu \mathrm{m}$ filter before analysis. The filtered water was mixed 1:1 with $50 \mathrm{mM}$ MES buffer (pH 6.0). The sensing kinetics were measured in a 96-well plate with a final of $100 \mu \mathrm{L}$ sample containing $50 \mathrm{nM}$ sensor probe. The sensor fluorescence background was monitored for $10 \mathrm{~min}$ before spiking the samples with various concentrations of $\mathrm{Cu}^{2+}$.

\section{Results and Discussion}

In vitro selection. To isolate a $\mathrm{Cu}^{2+}$-specific DNAzyme, in vitro selection was carried out using a library containing fifty random nucleotides $\left(\mathrm{N}_{50}\right.$, Figure $\left.1 \mathrm{~A}\right)$. The embedded cleavage junction is denoted by $\mathrm{rA}^{*} \mathrm{G}$, where $\mathrm{rA}$ is an RNA adenine nucleotide and the asterisk represents a phosphorothioate (PS) modification. Since RNA is approximately one-million-fold less stable compared to DNA, ${ }^{41}$ cleavage is most likely to occur at this single RNA linkage site. This PS modification is for recruiting the thiophilic $\mathrm{Cu}^{2+}$ to the scissile phosphate for the cleavage reaction. Since this PS modification was at the fixed region of the library, the selection method was the same as normal selections. The initial library contained $\sim 10^{13}$ random DNA sequences, and we hoped to isolate a sub-population that can selectively use $\mathrm{Cu}^{2+}$ for cleavage. 
We previously reported a DNAzyme named Ce13d that cleaves the normal phosphodiester RNA linkage in the presence of trivalent lanthanides. ${ }^{31}$ With the PS modification at the cleavage site, $\mathrm{Ce} 13 \mathrm{~d}$ becomes active with all thiophilic metals including $\mathrm{Cu}^{2+} .42$ The sequence of $\mathrm{Ce} 13 \mathrm{~d}$ is shown in Figure 2D, and it contains a stretch of 16 highly conserved nucleotides (in red). ${ }^{31,43,44}$ Since Ce13d lacks specificity for $\mathrm{Cu}^{2+}$, this sequence needed to be eliminated during the selection. Therefore, prior to the metal addition step, the library was hybridized to a short piece of DNA complementary to the conserved region in all our selections. In this way, the Ce13d sequence is deactivated and can later be removed from the library. The detailed selection protocols have been described previously. ${ }^{34}$

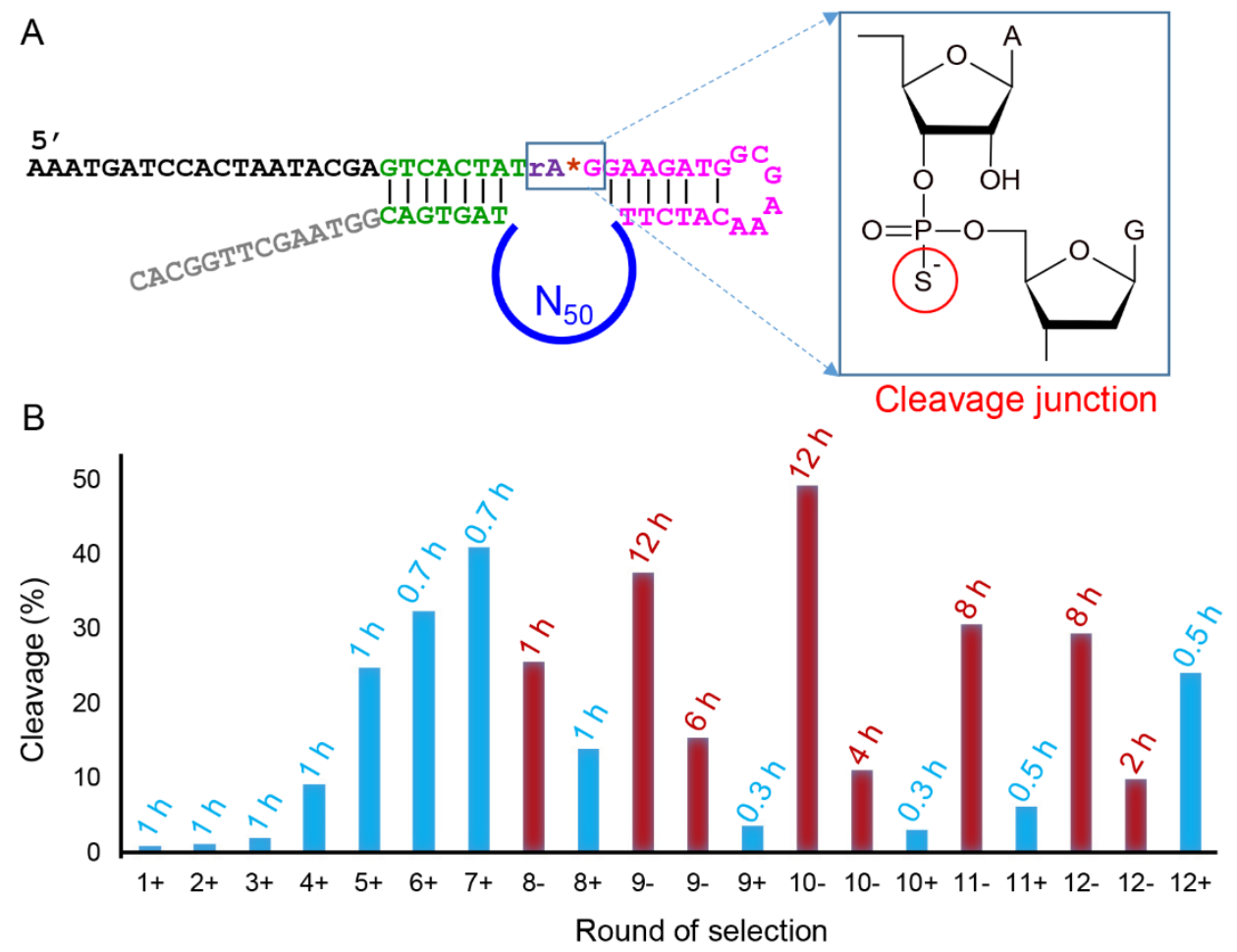

Figure 1. (A) The sequence of the library used for the in vitro selection of $\mathrm{Cu}^{2+}$-specific DNAzymes cleaving the PS-RNA linkage (denoted by an asterisk and its structure is also given). (B) Progress of the selection. The selection rounds are marked with a plus sign and a blue bar 
(indicating positive selection using $\mathrm{Cu}^{2+} ; 50 \mu \mathrm{M} \mathrm{Cu}^{2+}$ for the first 8 rounds, $20 \mu \mathrm{M} \mathrm{Cu}^{2+}$ for round 9 and 10 rounds, and $10 \mu \mathrm{M} \mathrm{Cu}^{2+}$ for the last 2 rounds); or with a minus sign and a red bar (indicating negative selection using a mixture of $\mathrm{Cd}^{2+}, \mathrm{Pb}^{2+}$ and $\mathrm{Zn}^{2+}(20 \mu \mathrm{M}$ each) for round 810 , and $\mathrm{Cd}^{2+}$ alone $(10 \mu \mathrm{M})$ for round 11-12). In some rounds, two negative selections were performed in tandem to improve metal specificity for $\mathrm{Cu}^{2+}$. The incubation times of each round are also marked.

After adding $\mathrm{Cu}^{2+}$ to the library, a fraction of the library could have been cleaved, resulting in a shorter sequence. These cleaved sequences were readily harvested after performing a denaturing gel electrophoresis and amplified using two rounds of PCR to reconstruct the library. The progress of the selection is presented in Figure 1B. At the end of round 7, the library achieved $\sim 40 \%$ cleavage yield with $50 \mu \mathrm{M} \mathrm{Cu}^{2+}$. However, at the same time, the library was also active with other thiophilic metals. For example, after $1 \mathrm{~h}$ incubation with a metal mixture of $\mathrm{Cd}^{2+}, \mathrm{Zn}^{2+}$, and $\mathrm{Pb}^{2+}, 25 \%$ cleavage was observed (the first red bar in Figure 1B). To achieve a high metal specificity, we then carried out extensive negative selections, where the population active with $\mathrm{Cd}^{2+}$ and $\mathrm{Pb}^{2+}$ and $\mathrm{Zn}^{2+}$ were removed, and the remaining uncleaved population were harvested for the positive $\mathrm{Cu}^{2+}$ selection. To push the selectivity limit, negative selections were incubated for a long time (up to $12 \mathrm{~h}$ and sometimes done consecutively). To push for high $\mathrm{Cu}^{2+}$ activity, the positive selections were incubated for only $0.5 \mathrm{~h}$ or less.

Search for active DNAzymes. At the end of round 12, the library was analyzed using deep sequencing. The resulting 23,505 sequences were clustered into different families using the Geneious program. The representative sequences from the 22 most populated families are aligned in Table S3, in which each sequence was individually folded using Mfold. ${ }^{45}$ Among them, twelve 
can be truncated into reasonable secondary structures. These were then used to construct transcleaving DNAzymes and individually tested (see Figure S2 for their trans-cleaving structures). All these DNAzymes share the same substrate sequence that is labeled with a FAM fluorophore.

Our goal was to identify the best candidate for $\mathrm{Cu}^{2+}$ detection. First, the activity of these sequences were tested with $\mathrm{Cu}^{2+}$. The gel analysis showed that the PSCu3, 6, 9, 10, and 18 DNAzymes have high activity (nearly $50 \%$ cleavage) in all the tested conditions (Figure S3), indicating the success of our in vitro selection. To further narrow down the candidate for $\mathrm{Cu}^{2+}$ sensing, we next screened for $\mathrm{Cu}^{2+}$ selectivity. These five active DNAzymes were then tested against 1 or $10 \mu \mathrm{M}$ of $\mathrm{Cu}^{2+}, \mathrm{Cd}^{2+}, \mathrm{Pb}^{2+}$, or $\mathrm{Hg}^{2+}$ for 10 min (Figure S4). From this experiment, $\mathrm{PSCu} 9$ and PSCu10 were studied further for their highest selectivity for $\mathrm{Cu}^{2+}$. Although PSCu3 is also highly active with $\mathrm{Cu}^{2+}$, it has lower selectivity and was thus abandoned.

The secondary structures of PSCu10 and PSCu9 are shown in Figure 2A and 2C, respectively. An interesting feature is the very small enzyme loop of PSCu10, containing only 8 nucleotides. A few other active DNAzymes also have some sequence similarity and they are aligned in Figure 2B for comparison of these core sequences (color coding matches that in Figure 2A). PSCu9 has a hairpin structure, which is also typically seen for many RNA-cleaving DNAzymes. ${ }^{28,31}$ Aside from this hairpin, PSCu9 has only four nucleotides in the enzyme loop, and it is also a very small DNAzyme. 

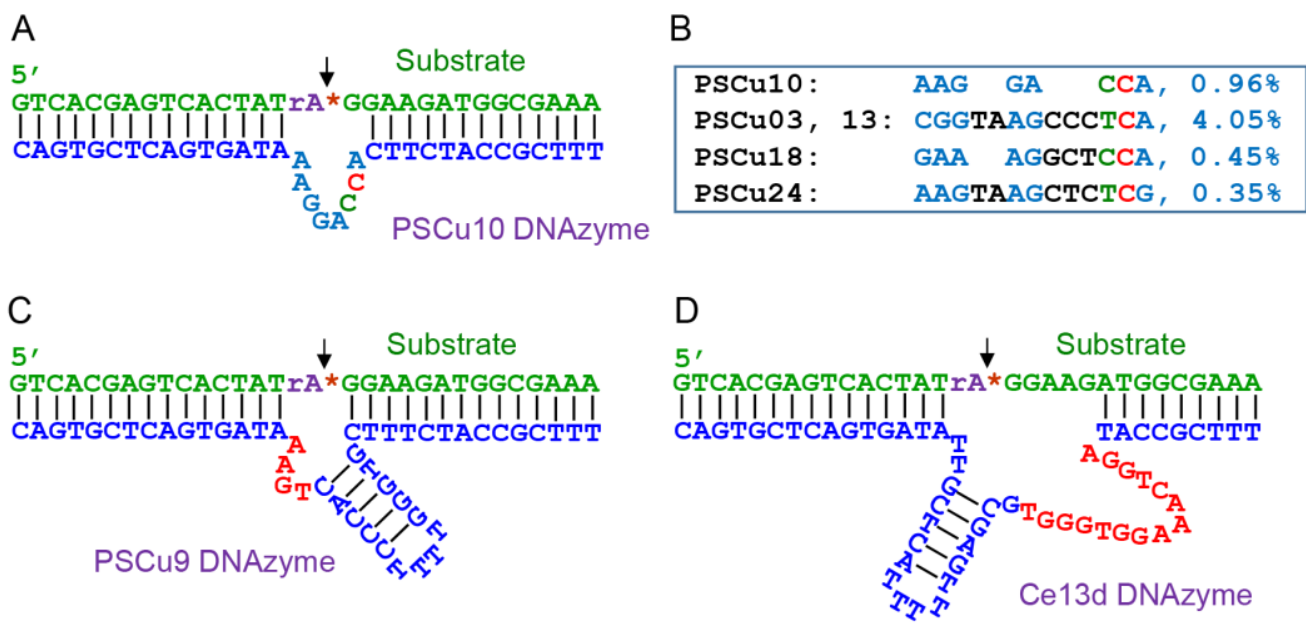

Figure 2. The secondary structures of (A) the PSCu10, (C) the PSCu9, and (D) the Ce13d DNAzymes. They all cleave the PS-RNA substrate in the presence of $\mathrm{Cu}^{2+}$. (B) Alignment of the catalytic core sequences of three active DNAzymes based on PSCu10. The color code matches with that in (A). The percentage of each sequence in the final library is also shown.

Biochemical characterizations. So far, two DNAzyme candidates that work efficiently in the presence of $\mathrm{Cu}^{2+}$ were identified. Next, biochemical studies were performed to further understand them. First, these two DNAzymes were tested in the presence of various concentrations of $\mathrm{Cu}^{2+}$ (Figure 3A). Both DNAzymes show $\mathrm{Cu}^{2+}$ concentration dependent cleavage, and PSCu10 is more sensitive, yielding saturated cleavage with just $1 \mu \mathrm{M} \mathrm{Cu}^{2+}$ (Figure 3C). On the other hand, $\mathrm{PSCu} 9$ produces maximal cleavage with $10 \mu \mathrm{M} \mathrm{Cu}^{2+}$. At even higher $\mathrm{Cu}^{2+}$ concentrations, a slight inhibition effect is observed for both DNAzymes. That is likely due to non-specific $\mathrm{Cu}^{2+}$ binding to DNA bases to disrupt DNAzyme folding. Subsequently, the DNAzyme kinetics at their respectively optimal $\mathrm{Cu}^{2+}$ concentrations were measured. $\mathrm{PSCu} 9$ has a cleavage rate of $0.093 \mathrm{~min}^{-}$ ${ }^{1}$ with $10 \mu \mathrm{M} \mathrm{Cu}^{2+}$ (Figure 3C, blue dots), and this rate is similar to that of PSCu10 with $1 \mu \mathrm{M} \mathrm{Cu}^{2+}$ (Figure 3D, blue dots, $0.085 \mathrm{~min}^{-1}$ ). 
Next, the kinetics of the other thiophilic metal ions were also measured. Both DNAzymes have essentially no activity in the presence of $\mathrm{Cd}^{2+}$. For $\mathrm{PSCu} 9, \mathrm{~Pb}^{2+}$ has a significant amount of cleavage $\left(0.003 \mathrm{~min}^{-1}, \sim 30\right.$-fold slower than $\left.\mathrm{Cu}^{2+}\right)$, while $\mathrm{PSCu} 10$ is nearly inactive with $\mathrm{Pb}^{2+}$. Both DNAzymes cleave very quickly in the presence of $\mathrm{Hg}^{2+}$, which is expected since $\mathrm{Hg}^{2+}$ can cleave the PS-RNA substrate even without the enzyme strand present. ${ }^{46,47}$ Since the $\mathrm{Hg}^{2+}$ cleavage is finished almost instantaneously, this kinetic signature can be used to distinguish $\mathrm{Hg}^{2+}$ from $\mathrm{Cu}^{2+}$ (vide infra). Overall, it appears that PSCu10 is the best candidate in terms of sensitivity and selectivity for $\mathrm{Cu}^{2+}$ detection and it was chosen for further studies. The cleavage yield with other common metal ions are also compared, including $\mathrm{Cu}^{+}$(Figure 3E). While $\mathrm{Cu}^{+}$has lower cleavage yield than $\mathrm{Cu}^{2+}$ at $1 \mu \mathrm{M}$, they reached a similar cleavage at $10 \mu \mathrm{M}$. The $\mathrm{Cu}^{+}$salt used in this work was tetrakis(acetonitrile)copper(I) hexafluorophosphate, which is a commonly used source for $\mathrm{Cu}^{+}$. We suspected that at a low salt concentration, this $\mathrm{Cu}^{+}$salt would be quickly oxidized to $\mathrm{Cu}^{2+}$ by the oxygen in water. To test this hypothesis, $\mathrm{Cu}^{+}$was generated in situ by reacting $\mathrm{Cu}^{2+}$ with ascorbate (Figure S5). In the presence of ascorbate, neither $\mathrm{Cu}^{2+}$ nor this $\mathrm{Cu}^{+}$salt produced any cleavage, thus confirming the selectivity of PSCu10 to $\mathrm{Cu}^{2+}$. This is understandable since PSCu10 is a transesterification DNAzyme that does not perform oxidative cleavage. This is in sharp contrast to the previously reported $\mathrm{Cu}^{2+}$ sensor, which used an oxidative DNA-cleaving DNAzyme requiring ascorbate. ${ }^{17,}{ }^{18}$ Most other metals do not promote cleavage (except $\mathrm{Hg}^{2+}$ and high concentrations of $\mathrm{Pb}^{2+}$ ). If the PS substrate was replaced with the $\mathrm{PO}$ analog, none of the metals produced any cleavage (Figure 3F). 

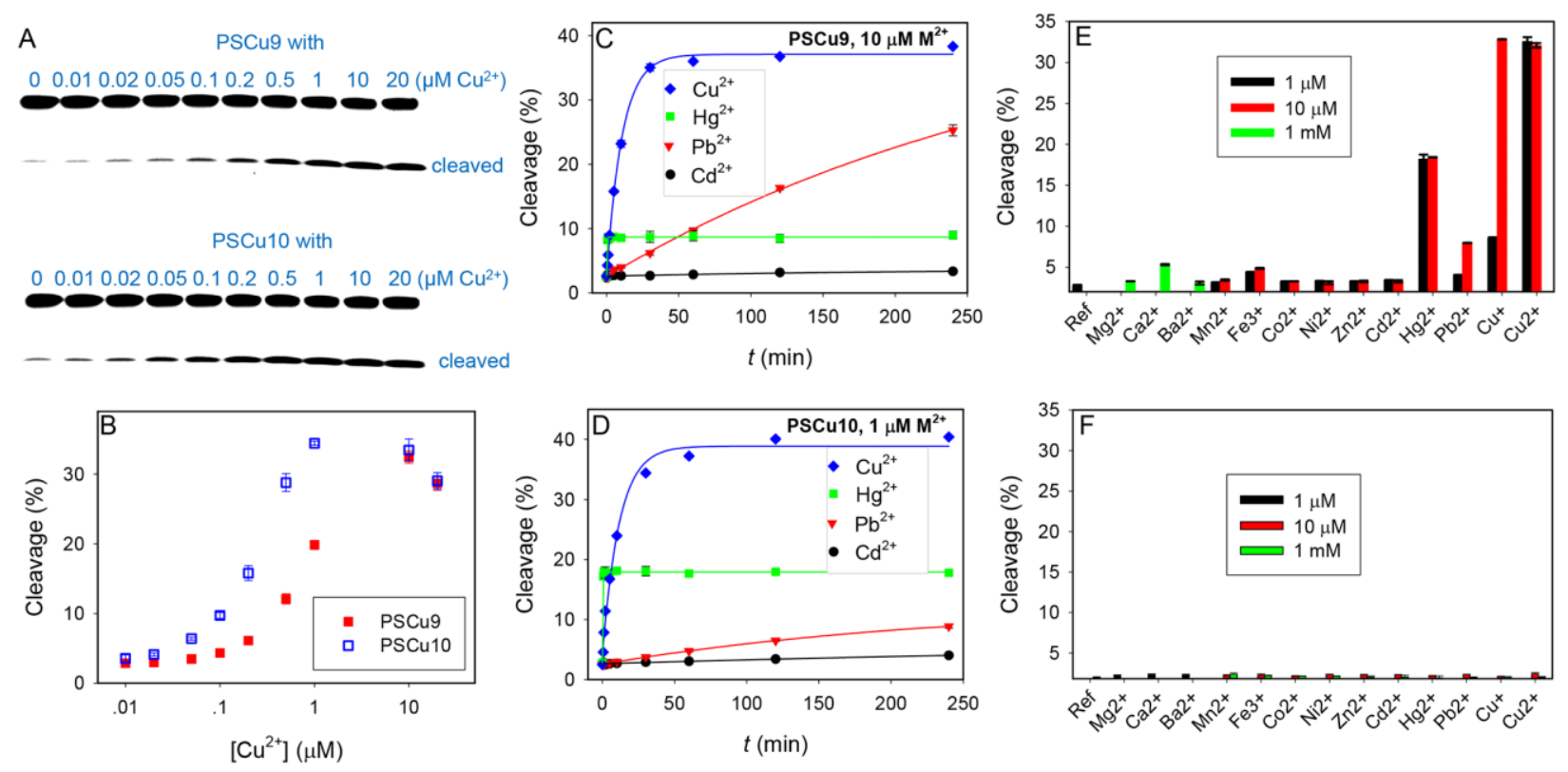

Figure 3. (A) Gel images of PSCu9 and PSCu10 cleaving the PS-RNA substrate in the presence of various concentrations of $\mathrm{Cu}^{2+}$. (B) Quantification of the cleavage yield as a function of $\mathrm{Cu}^{2+}$ concentration for these two DNAzymes. Cleavage kinetics of (C) PSCu9 and (D) PSCu10 in the presence of four thiophilic metals. Cleavage yield of PSCu10 in the presence of various metal ions at a few different concentrations with (E) the PS substrate and (F) the PO substrate.

PS diastereomer preference. In all the above assays, the cleavage yield never exceeded 50\%, and this is likely due to the chiral phosphorus center at the PS modification site (Figure 4A). In our selection and all the above assays, a mixture of the two diastereomers was used. To study the activity of each individual isomer, the substrate was prepared after HPLC separation. The assignment of each isomer was published previously. ${ }^{34}$ The $R_{\mathrm{p}}$ substrate has a rate of $0.10 \mathrm{~min}^{-1}$ with CuPS10, while the $S_{\mathrm{p}}$ has a rate of $0.0028 \mathrm{~min}^{-1}$ (37-fold slower, see Figure S6 for its full kinetic trace measured over 1 day). The $R_{\mathrm{p}}$ rate measured here is slightly faster than that for the mixture $\left(0.085 \mathrm{~min}^{-1}\right)$, since the latter is an averaged value. Therefore, PSCu10 uses the $R_{\mathrm{p}}$ sulfur 
to bind $\mathrm{Cu}^{2+}$, which is similar to most known RNA-cleaving DNAzymes and ribozymes. ${ }^{34,48,49}$ Using the separated $R_{\mathrm{p}}$ substrate, PSCu10 indeed achieved over 50\% cleavage yield (Figure 4C), and the cleavage at low $\mathrm{Cu}^{2+}$ concentrations is shown in Figure 4D (linear regression equation: $y$ $=6.80+0.268 x)$. Even $10 \mathrm{nM} \mathrm{Cu}^{2+}$ produced a significant amount of cleavage.

This information is useful for biosensor development since the $S_{\mathrm{p}}$ half of the substrate does not contribute much to the signal but to the background. The PO substrate (Figure $4 \mathrm{~B}$, black triangles) was also tested, and it is completely inactive. Therefore, the presence of the PS modification is critical for PSCu10.
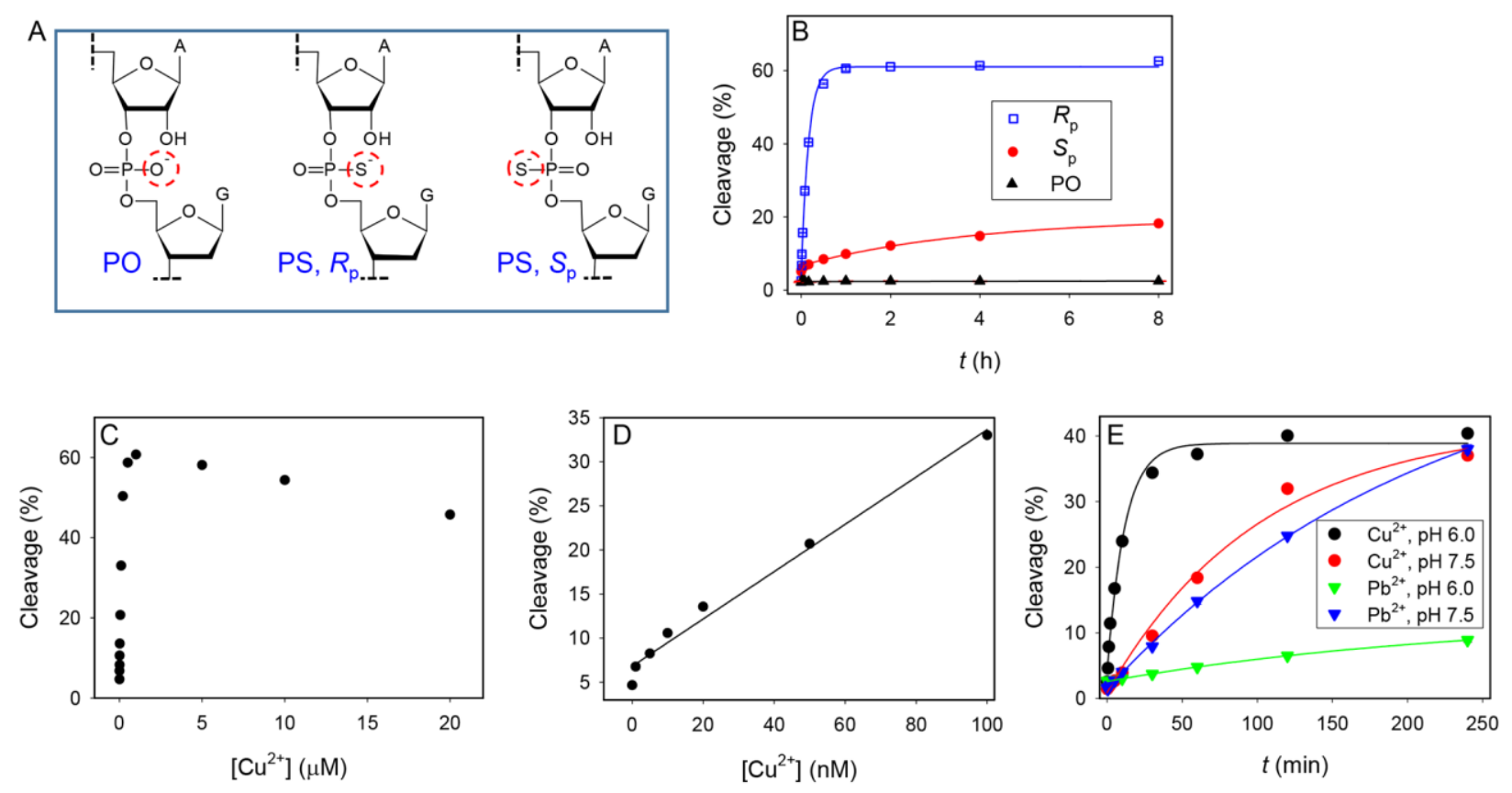

Figure 4. (A) The structures of the three types of cleavage junctions. The normal phosphodiester junction is called PO and the PS junction contains two diastereomers. (B) Kinetics of PSCu10 with $1 \mu \mathrm{M} \mathrm{Cu}{ }^{2+}$ cleaving these three types of junctions. Cleavage yield of PSCu10 for the purified $R_{\mathrm{p}}$ substrate as a function of $\mathrm{Cu}^{2+}$ concentration (C) and the low $\mathrm{Cu}^{2+}$ concentration region (D). (E) 
Kinetics of PSCu10 cleaving the PS substrate (mixture of $R_{\mathrm{p}}$ and $S_{\mathrm{p}}$ ) at two pH values with $1 \mu \mathrm{M}$ $\mathrm{Cu}^{2+}$ or $1 \mu \mathrm{MPb}^{2+}$.

A biosensor for $\mathrm{Cu}^{2+}$. With the PSCu10 DNAzyme, a biosensor for $\mathrm{Cu}^{2+}$ detection was designed using the catalytic beacon strategy. ${ }^{50}$ The substrate strand was labeled with a FAM fluorophore and the corresponding end of the enzyme was labeled with a dark quencher (Figure 5A). In the presence of $\mathrm{Cu}^{2+}$, the cleavage reaction takes place and the signal is increase after release of the cleavage fragment. Since FAM is a $\mathrm{pH}$-sensitive fluorophore and it has the highest fluorescence at $\mathrm{pH}$ above 7.5, we first tested the sensor at $\mathrm{pH} 7.5$. While $\mathrm{Cu}^{2+}$-dependent signal increase was observed, a strong interference from $\mathrm{Pb}^{2+}$ was found (Figure $\mathrm{S} 7$ ), which is inconsistent with the gel-based activity assay at $\mathrm{pH}$ 6.0. Therefore, we compared the activity of $\mathrm{Cu}^{2+}$ and $\mathrm{Pb}^{2+}$ at $\mathrm{pH} 6.0$ and $\mathrm{pH} 7.5$ (Figure 4E). Interestingly, the $\mathrm{Cu}^{2+}$ activity dropped at a higher $\mathrm{pH}$, while the $\mathrm{Pb}^{2+}$ activity increased. Therefore, for $\mathrm{Cu}^{2+}$ detection, $\mathrm{pH} 6.0$ is the optimal condition.

The sensor signaling kinetics was measured at $\mathrm{pH} 6.0$ at various $\mathrm{Cu}^{2+}$ concentrations (Figure 5B). Even $5 \mathrm{nM} \mathrm{Cu}^{2+}$ produced an obvious signal increase and saturated response occurred beyond $200 \mathrm{nM} \mathrm{Cu}^{2+}$. The initial signaling rate after $\mathrm{Cu}^{2+}$ addition was plotted (Figure 5C), and the response can be fitted to a single $\mathrm{Cu}^{2+}$ binding with an apparent $K_{\mathrm{d}}$ of $105 \mathrm{nM} \mathrm{Cu}{ }^{2+}$. At low $\mathrm{Cu}^{2+}$ concentrations, the response was linear (inset of Figure 5C; linear regression equation: $y=$ $0.0175+0.00345 x)$. The detection limit was calculated to be $1.6 \mathrm{nM} \mathrm{Cu}^{2+}$ based on $3 \sigma /$ slope, where $\sigma$ is the background variation of the sensor in the absence of $\mathrm{Cu}^{2+}$. This is over 20 times more sensitive compared to the previously reported DNA-cleaving DNAzyme $\mathrm{Cu}^{2+}$ sensor. ${ }^{17} \mathrm{We}$ compared our sensor with many representative $\mathrm{Cu}^{2+}$ optical sensors reported in the literature (Table 
S4), and our sensor has the best detection limit. The relative standard deviation is typically below $10 \%$. The noisy kinetic traces in Figure 5B is due to the low $\mathrm{pH}$ condition. If the FAM label is replaced by a pH-insensitive fluorophore, the fluorescence signal should be stronger. We did not try higher sensor concentration to improve signal for cost reasons. The US EPA defined maximal contamination level for copper in water is $20 \mu \mathrm{M}(1.3 \mathrm{ppm})$, which is much higher than the detection limit of our sensor. Such high sensitivity allows sufficient sample dilution to remove the sample matrix effect.

Next, the sensor response to $500 \mathrm{nM}$ of various competing metal ions was measured (Figure 5D). $\mathrm{Cu}^{2+}$ and $\mathrm{Cu}^{+}$produced a similar response. As explained above, this $\mathrm{Cu}^{+}$response should be due to its oxidation to $\mathrm{Cu}^{2+}$ at low metal concentrations. With $50 \mu \mathrm{M}$ ascorbate, neither $\mathrm{Cu}^{2+}$ nor $\mathrm{Cu}^{+}$produced any signal (Figure $5 \mathrm{~F}$ ). $\mathrm{Hg}^{2+}$ also produced a high signal, but it has a kinetic signature of an instant rise followed by a flat response. When fitting the slope, the initial $20 \mathrm{sec}$ was filtered out, and the $\mathrm{Hg}^{2+}$ interference was removed (Figure 5E). The response of this sensor to $\mathrm{Cu}^{2+}$ in Lake Ontario water was also tested, and a high sensitivity was achieved (Figure S8).

A
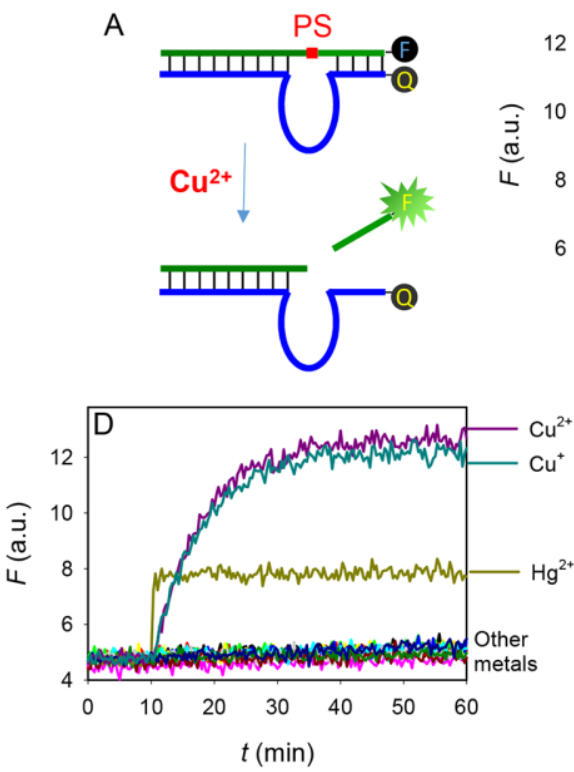
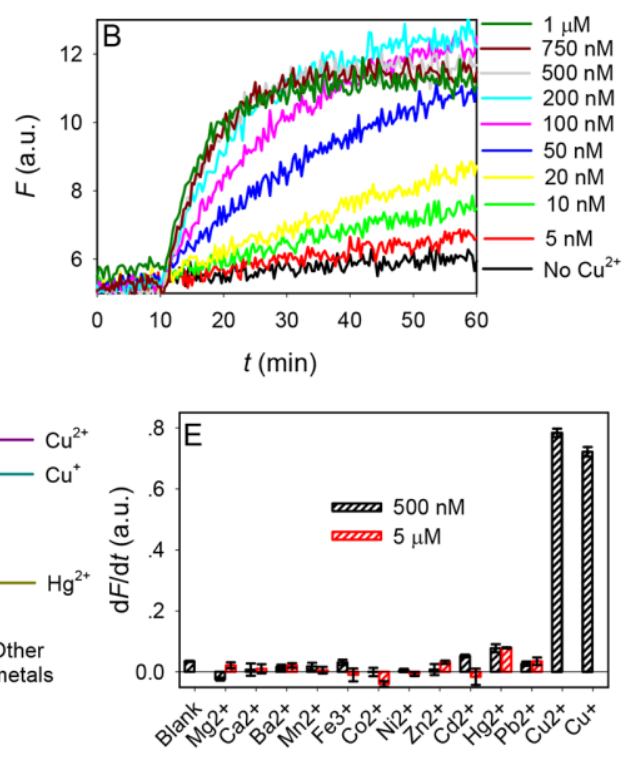
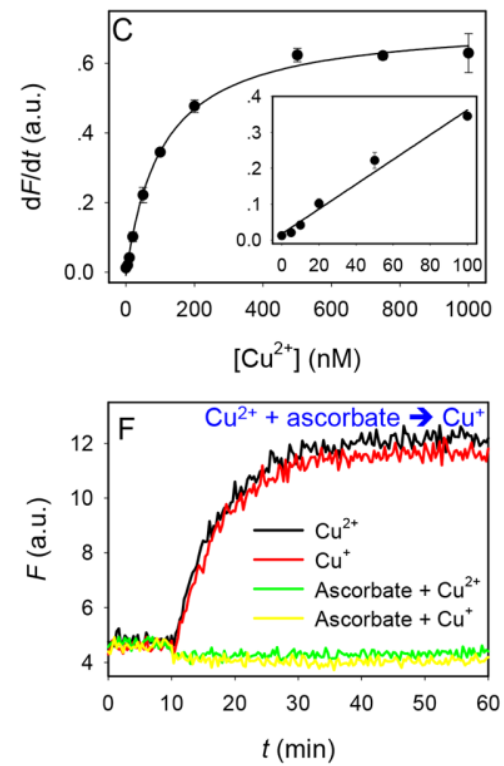
Figure 5. (A) Schematic representation of the fluorescent DNAzyme beacon for $\mathrm{Cu}^{2+}$ detection. (B) Kinetics of sensor fluorescence enhancement with various concentrations of $\mathrm{Cu}^{2+}$. (C) Quantification of $\mathrm{Cu}^{2+}$ based on the initial rate of sensor fluorescence enhancement (from 1 to 6 min after $\mathrm{Cu}^{2+}$ addition). Inset: the initial linear response at low $\mathrm{Cu}^{2+}$ concentrations. (D) Sensor response to $500 \mathrm{nM}$ divalent and trivalent metal ions. The list of the other metal ions tested can be found in Figure 2E. (E) Sensor selectivity quantification at two metal ion concentrations. (F) Sensor response to $500 \mathrm{nM}$ of $\mathrm{Cu}^{+}$or $\mathrm{Cu}^{2+}$ in the presence of $50 \mu \mathrm{M}$ ascorbate.

\section{Conclusions.}

In summary, in vitro selection was performed to search for a DNAzyme cleaving a PS-RNA substrate in the presence of $\mathrm{Cu}^{2+}$. A new DNAzyme named PSCu10 was identified with excellent affinity and specificity for $\mathrm{Cu}^{2+}$. PSCu10 works optimally with the $R_{\mathrm{p}}$ diastereomer of the PS substrate, which is 37-times faster than the $S_{\mathrm{p}}$ form, while the PO form is inactive. Using this DNAzyme, a $\mathrm{Cu}^{2+}$ sensor was designed with a detection limit of $1.6 \mathrm{nM} \mathrm{Cu}^{2+}$. It has no activity in the presence of ascorbate, suggesting that it is specific for $\mathrm{Cu}^{2+}$ instead of $\mathrm{Cu}^{+}$. This is in sharp contrast to a previous sensor based on oxidative DNA cleavage, which requires ascorbate. This DNAzyme is useful as a probe for measuring $\mathrm{Cu}^{2+}$ in water and also for understanding $\mathrm{Cu}^{2+}$ binding to DNA. This study indicates that PS-modification at the cleavage site is a valuable method for isolating DNAzymes for detecting thiophilic metal ions. 


\section{Acknowledgments}

Funding for this work is from the Ontario Ministry of Research \& Innovation, and the Natural Sciences and Engineering Research Council (NSERC) of Canada (Discovery Grant and Strategic Project Grant).

Supporting Information Available: DNA sequences, additional DNAzyme characterization data, sensing in Lake Ontario water, and other literature reported $\mathrm{Cu}^{2+}$ sensor performance. This information is available free of charge via the Internet at http://pubs.acs.org/.

\section{References}

(1) Georgopoulos, P. G.; Roy, A.; Yonone-Lioy, M. J.; Opiekun, R. E.; Lioy, P. J. J. Toxicol. Env. Health, B: 2001, 4, 341 .

(2) Zhao, Y.; Zhang, X.-B.; Han, Z.-X.; Qiao, L.; Li, C.-Y.; Jian, L.-X.; Shen, G.-L.; Yu, R.Q. Anal. Chem. 2009, 81, 7022-7030.

(3) Zhou, Y.; Wang, F.; Kim, Y.; Kim, S.-J.; Yoon, J. Org. Lett. 2009, 11, 4442-4445.

(4) Zeng, L.; Miller, E. W.; Pralle, A.; Isacoff, E. Y.; Chang, C. J. J. Am. Chem. Soc. 2006, $128,10$.

(5) Torrado, A.; Walkup, G. K.; Imperiali, B. J. Am. Chem. Soc. 1998, 120, 609-610.

(6) Wegner, S. V.; Arslan, H.; Sunbul, M.; Yin, J.; He, C. J. Am. Chem. Soc. 2010, 132, 2567-+.

(7) Lan, G. Y.; Huang, C. C.; Chang, H. T. Chem. Commun. 2010, 46, 1257-1259.

(8) Liu, J.; Cao, Z.; Lu, Y. Chem. Rev. 2009, 109, 1948-1998. 
(9) Zhang, X.-B.; Kong, R.-M.; Lu, Y. Annu. Rev. Anal. Chem. 2011, 4, 105-128.

(10) Willner, I.; Shlyahovsky, B.; Zayats, M.; Willner, B. Chem. Soc. Rev. 2008, 37, 11531165.

(11) Navani, N. K.; Li, Y. Curr. Opin. Chem. Biol. 2006, 10, 272-281.

(12) Sigel, R. K. O.; Sigel, H. Acc. Chem. Res. 2010, 43, 974-984.

(13) Sigel, R. K. O.; Pyle, A. M. Chem. Rev. 2007, 107, 97-113.

(14) Ward, W. L.; Plakos, K.; DeRose, V. J. Chem. Rev. 2014, 114, 4318-4342.

(15) Lu, Y. Chem. Eur. J. 2002, 8, 4588-4596.

(16) Liu, J. Can. J. Chem. 2015, 93, 273-278.

(17) Liu, J.; Lu, Y. J. Am. Chem. Soc. 2007, 129, 9838-9839.

(18) Carmi, N.; Balkhi, H. R.; Breaker, R. R. Proc. Natl. Acad. Sci. U.S.A. 1998, 95, 22332237.

(19) Liu, J.; Lu, Y. Chem. Commun. 2007, 4872-4874.

(20) Cuenoud, B.; Szostak, J. W. Nature 1995, 375, 611-614.

(21) Schlosser, K.; Li, Y. Biochemistry 2004, 43, 9695-9707.

(22) Wang, M.; Zhang, H.; Zhang, W.; Zhao, Y.; Yasmeen, A.; Zhou, L.; Yu, X.; Tang, Z. Nucleic Acids Res. 2014, 42, 9262-9269.

(23) Torabi, S.-F.; Wu, P.; McGhee, C. E.; Chen, L.; Hwang, K.; Zheng, N.; Cheng, J.; Lu, Y. Proc. Natl. Acad. Sci. U.S.A. 2015, 112, 5903-5908.

(24) Zhou, W.; Saran, R.; Chen, Q.; Ding, J.; Liu, J. ChemBioChem 2015, DOI: 10.1002/cbic.201500603.

(25) Breaker, R. R.; Joyce, G. F. Chem. Biol. 1994, 1, 223-229.

(26) Lan, T.; Furuya, K.; Lu, Y. Chem. Commun. 2010, 46, 3896-3898. 
(27) Li, J.; Zheng, W.; Kwon, A. H.; Lu, Y. Nucleic Acids Res. 2000, 28, 481-488.

(28) Liu, J.; Brown, A. K.; Meng, X.; Cropek, D. M.; Istok, J. D.; Watson, D. B.; Lu, Y. Proc. Natl. Acad. Sci. U.S.A. 2007, 104, 2056-2061.

(29) Huang, P.-J. J.; Vazin, M.; Matuszek, Ż.; Liu, J. Nucleic Acids Res. 2015, 43, 461-469.

(30) Huang, P.-J. J.; Vazin, M.; Liu, J. Anal. Chem. 2014, 86, 9993-9999.

(31) Huang, P.-J. J.; Lin, J.; Cao, J.; Vazin, M.; Liu, J. Anal. Chem. 2014, 86, 1816-1821.

(32) Hollenstein, M.; Hipolito, C.; Lam, C.; Dietrich, D.; Perrin, D. M. Angew. Chem., Int. Ed. 2008, 47, 4346 - 4350 .

(33) Santoro, S. W.; Joyce, G. F.; Sakthivel, K.; Gramatikova, S.; Barbas, C. F., III J. Am. Chem. Soc. 2000, 122, 2433-2439.

(34) Huang, P.-J. J.; Liu, J. Nucleic Acids Res. 2015, 43, 6125-6133.

(35) Deleavey, Glen F.; Damha, M. J. Chem. Biol. 2012, 19, 937-954.

(36) Thaplyal, P.; Ganguly, A.; Hammes-Schiffer, S.; Bevilacqua, P. C. Biochemistry 2015, $54,2160-2175$.

(37) Wang, S.; Karbstein, K.; Peracchi, A.; Beigelman, L.; Herschlag, D. Biochemistry 1999, $38,14363-14378$.

(38) Lee, J. H.; Wernette, D. P.; Yigit, M. V.; Liu, J.; Wang, Z.; Lu, Y. Angew. Chem. Int. Ed. 2007, 46, 9006-9010.

(39) Farlow, J.; Seo, D.; Broaders, K. E.; Taylor, M. J.; Gartner, Z. J.; Jun, Y.-w. Nat. Methods 2013, 10, 1203-1205.

(40) Ma, N.; Sargent, E. H.; Kelley, S. O. Nat. Nanotechnol. 2009, 4, 121-125.

(41) Li, Y.; Breaker, R. R. J. Am. Chem. Soc. 1999, 121, 5364-5372.

(42) Huang, P.-J. J.; Liu, J. Anal. Chem. 2014, 86, 5999-6005. 
(43) Vazin, M.; Huang, P.-J. J.; Matuszek, Ż.; Liu, J. Biochemistry 2015, 54, 6132-6138.

(44) Zhou, W.; Zhang, Y.; Huang, P.-J. J.; Ding, J.; Liu, J. Nucleic Acids Res. 2015. DOI: 10.1093/nar/gkv1346

(45) Zuker, M. Nucleic Acids Res. 2003, 31, 3406-3415.

(46) Huang, P.-J. J.; Wang, F.; Liu, J. Anal. Chem. 2015, 87, 6890-6895.

(47) Huang, P.-J. J.; Vazin, M.; Liu, J. Anal. Chem. 2015, 87, 10443-10449

(48) Thaplyal, P.; Ganguly, A.; Golden, B. L.; Hammes-Schiffer, S.; Bevilacqua, P. C. Biochemistry 2013, 52, 6499-6514.

(49) Nawrot, B.; Widera, K.; Sobczak, M.; Wojcik, M.; Stec, W. J. Curr. Org. Chem. 2008, 12, 1004-1009.

(50) Li, J.; Lu, Y. J. Am. Chem. Soc. 2000, 122, 10466-10467. 